\title{
La Iglesia católica y la formación del Estado-nación en América Latina en el siglo XIX. El caso colombiano
}

The Catholic Church and the

Formation of the Nacion-State in

Nineteenth-century Latin America.

The Case of Colombia

\author{
Luis Javier Ortiz Mesa \\ Profesor Titular en la \\ Universidad Nacional de Colombia \\ (UNAL - Medellín/Colombia) \\ e-mail: ljortiz@unal.edu.co
}

\begin{abstract}
Resumen
El artículo ofrece una mirada sobre el papel de la Iglesia católica en el proceso de formación del Estado-nación en la Colombia del siglo XIX, a través de tres períodos. Un primer período, entre 1810 y 1853, cuando se produjo la participación activa de los miembros de la Iglesia en los procesos de independencia (1810 y 1824) y cuando, dado el peso decisivo de la Iglesia en la formación de las mentalidades neogranadinas desde la Colonia y en la delimitación partidista, el Estado naciente la sometió al Patronato republicano entre 1824 y 1853. Un segundo período, con difíciles procesos de secularización durante los gobiernos liberales, partió de la separación de la Iglesia y el Estado en 1853 y culminó en 1885. Finalmente, un tercer período revela la recuperación del papel dominante de la Iglesia católica en la sociedad colombiana bajo la Regeneración conservadora, entre 1886 y 1902, en contravía de los procesos de secularización que se dieron en los demás países de América Latina.
\end{abstract}

\begin{abstract}
The article examines the role of the Catholic Church in the formation of the Colombia Nation State in three distinct periods during the 19th-century. In the first period (1810-1853) the members of the Church have an active participation in the processes of independence (1810 and 1824). Given the decisive role of the Church in the formation of new mentalities since the colonial times and in the also in the formation of parties, between 1824 and 1853 the nascent State subjugated the Church to the Republican patronage. A second period, with difficult processes of secularization during the Liberal governments, departed from the separation of the Church and State in 1853 and culminated in 1885 . Finally, a third period shows the recovery of the dominant role of the Catholic Church in the Colombian society under the conservative regeneration, between 1886 and 1902. The Colombia process ran against the processes of secularization that happened in the other Latin America countries.
\end{abstract}

Palabras-clave

Iglesia católica, Estado, Nación, Colombia, América Latina, siglo XIX

Keywords

Catholic Church, State, Nation, Colombia, Latin America, 19th century 
Agradezco a la Revista Almanack, a través de la profesora Lucía Bastos Pereira das Neves, la invitación a presentar este artículo como ponencia, para ser discutido en su sesión del 21 de noviembre de 2012 , en un ambiente exigente, cálido y afectuoso. A los profesores Guilherme Pereira das Neves y William de Souza Martins, quienes debatieron la ponencia, les agradezco sus análisis, comentarios y sugerencias, cuya pertinencia me permitió revisar el texto inicial y recomponer algunos de sus aspectos. Recibi el apoyo de Luisa Fernanda Álvarez García, estudiante de la Carrera de Historia de la Universidad Nacional de Colombia, Sede Medellin, para llevar a cabo la elaboración de este artículo, por lo que le doy mis reconocimientos. Van finalmente mis agradecimientos a mi colega Diana Luz Ceballos Gómez, quien leyó el primer borrador y me hizo sugerencias puntuales.

2

MELO, Jorge Orlando. Proceso de modernización en Colombia 1850-1930. En: Idem. Predecir el pasado: ensayos de historia de Colombia. Santa Fe de Bogotá: Fundación Simón y Lola Guberek, Colección Historia, 1992.

3

PALACIOS, Marco; SAFFORD, Frank. Colombia. País fragmentado, sociedad dividida. Su historia. Bogotá: Editorial Norma, 2002; MELO, Jorge Orlando. Op. Cit.
4

TIRADO MEJíA, Álvaro. Aspectos sociales de las guerras civiles en Colombia. Bogotá: Colcultura, 1976; ORTIZ MESA, Luis Javier. La sociedad colombiana en el siglo XIX. En: VELÁSOUEZ TORO, Magdala (dir.). Las mujeres en la historia de Colombia. Tomo II. Mujeres y sociedad. Bogotá: Norma, 1995
1. Aspectos de la sociedad colombiana en el siglo XIX ${ }^{1}$

Desde fines del siglo XVIII, la actual Colombia inició el camino que le permitiera construirse como sociedad moderna. Entre 1760 y 1850, los grupos dirigentes adoptaron la ideología liberal y establecieron un Estado independiente y, entre 1850 y 1930, el Estado se fortaleció, se configuró un mercado nacional, se constituyó una burguesía capaz de ejercer su dirección económica y política, y se integró el país al mercado mundial mediante el establecimiento de la producción cafetera. ${ }^{2}$ Durante el siglo XIX, el nuevo Estado, política y fiscalmente débil, se fue construyendo desigualmente en sus territorios por sus dos millones de habitantes en 1850 y sus cinco millones en 1912. El poder de la fuerza estatal estuvo muy distribuido en provincias y localidades, en un siglo de colonizaciones dinámicas. Para 1850, una cuarta parte de su 1.328.000 kilómetros cuadrados de territorio estaba roturado, mientras que para fines del siglo, casi un $40 \%$ ya lo estaba. El Estado logró, lenta y parcialmente, captar la lealtad de los dirigentes regionales y locales, en medio de tensiones que se produjeron entre el centro y la periferia, de tal manera que algunos territorios se adscribieron al Estado y otros no pudieron ser sometidos a las autoridades civiles, militares y eclesiásticas; en ellos imperaron sociedades sin ley, sin Dios, sin policía y sin impuestos, proclives a la guerra de guerrillas liberales, mientras las conservadoras se localizaron en las tierras altas del país. Los partidos políticos, el liberal y el conservador, cristalizados entre 1840 y 1860 , fueron junto con la Iglesia, con sus respectivas bases sociales, los dos principales pilares de formación nacional, en un país predominantemente mestizo y caracterizado por una modernización tradicionalista. ${ }^{3}$

La Iglesia católica con su presencia eficaz en una vasta geografía, sobre todo en las tierras altas de la cordillera oriental (Bogotá, Tunja, Pamplona), en la meseta del sur (Popayán y Pasto) y en el noroccidente (Antioquia), a través de sus bienes, parroquias, sacerdotes, comunidades religiosas y sociabilidades, continuó siendo la institución de mayor cohesión social durante el siglo. Sin embargo, esa presencia fue menos eficaz en las zonas costeras del Pacífico y del Atlántico, así como en buena parte de los valles interandinos y territorios ribereños del Magdalena, el Cauca, el Atrato, el Meta y el Orinoco. La Iglesia se constituyó en eje central de las diferenciaciones partidistas. Los liberales vieron en su autoridad, su poder simbólico, sus instituciones y mentalidades, construidas durante los tres siglos coloniales, un obstáculo para establecer una sociedad moderna. Por su parte, los conservadores la percibieron como un acicate para darle continuidad a una sociedad regida por la moral católica y por un orden de cristiandad. Tales diferencias y tensiones surgidas en esas relaciones de fuerza y lucha por disponer de la Iglesia o someterla, se conjugaron con contiendas electorales, disputas en torno a la organización estatal y territorial, rivalidades interregionales y locales, que dieron lugar a nueve guerras civiles en los años de 1830, 1839-42, 1851, 1854, 18591862, 1876-1877, 1885, 1895 y 1899-1902. ${ }^{4}$ No fue posible establecer un régimen que fundara la paz para consolidar un equilibrado desarrollo económico y social, y hubo que esperar a las primeras décadas del siglo XX para lograrlo parcialmente.

Así, el siglo XIX colombiano fue conflictivo por las pugnas por instaurar dos tipos de Estado, uno liberal y laico impulsado por grupos de letrados liberales, sobre todo abogados, médicos, algunos de ellos militares y unos pocos eclesiásticos, cuyas bases sociales fueron menores que las de 
5

GONZÁLEZ, Fernán. Poderes enfrentados. Iglesia y Estado en Colombia. Bogotá: Cinep, 1997.

6

PALACIOS, Marco. Entre la legitimidad y la violencia, Colombia, 1875-1994. Bogotá: Norma, 1995.

7

PASSERIN D'ENTRÉVES, Alessandro. La noción de Estado. Una introducción a la Teoría Política. Barcelona: Ariel, 2001.

8

ORTIZ MESA, Luis Javier et al. Ganarse el cielo defendiendo la religión. Guerras civiles en Colombia, 1840-1902. Bogotá: Unibiblos, 2005.

9

LYNCH, John. La formación de los Estados nuevos. En: LUCENA SALMORAL, Manuel (coord.). Historia de Iberoamérica. Tomo III: Historia contemporánea. Madrid: Cátedra, 1998. p.131247; Idem. La Iglesia católica, 1830-1930. En: BETHELL, Leslie (ed.). Historia de América Latina. Tomo VIII: América Latina, cultura y sociedad, 1830-1930. Barcelona: Crítica, 1991. p.65-122. sus contendores; otro, sustentado en la alianza de gran parte de la Iglesia católica con el partido conservador. Para algunos dirigentes liberales, la Iglesia se constituyó en un obstáculo para la búsqueda del progreso material e intelectual, por lo que buscaron sujetarla a su proyecto secularizador entre 1824 y 1885 . El resultado de este esfuerzo, que obtuvo respaldos limitados entre la población, predominantemente creyente, fue la identificación estrecha de la Iglesia con el partido conservador y la construcción de un Estado-nación fundado en el catolicismo y la herencia hispánica a partir de $1886 .^{5}$

La sociedad colombiana, durante el siglo XIX, al igual que las demás sociedades de América Latina, debió enfrentar un lento proceso de construcción de Estado-nación, que pasó necesariamente por cambios en las relaciones del Estado con la Iglesia, el ejército, los partidos, las provincias y las localidades. ${ }^{6}$ El naciente Estado debía disputar su posición con las instituciones y los organismos señalados y debió tomar medidas contundentes para debilitarlos o realizar transacciones que le fueran convenientes. Con la Iglesia debía combatir en el campo de la cohesión nacional, para convertirse en el nuevo referente de identificación de los ciudadanos; con el Ejército, para transformarse en el monopolizador de la fuerza; con los partidos, para regular sus acciones; y con las provincias y localidades, para consolidarse como autoridad jurídica y legislativa central; estas caracteristicas las debía adquirir el nuevo Estado para establecerse como poder estatal dominante. ${ }^{7}$ En este contexto, la Iglesia católica también debió buscar modalidades de adaptación, resistencia y reacción ante las nuevas condiciones del Estado en formación y, aunque relativamente debilitada, una vez concluidos los procesos de independencia, su peso en la sociedad fue preponderante, convirtiéndose en un factor de identidad nacional y de conflicto, dado que el nuevo Estado necesitaba de sus bienes pero también de su legitimidad, para moldear la nueva nación recién inventada. La Iglesia tuvo en Colombia un doble papel, actuó como una institución polarizadora de la vida política y social, al defender sus fueros y participar activamente en la creación de la opinión pública, las elecciones y las guerras civiles y, al tiempo, se constituyó en fuerza civilizadora, al irradiar sus sociabilidades por la geografía nacional, crear instituciones para la educación y la beneficencia, y atender sus campos de misión mediante "la evangelización de salvajes" realizada por comunidades religiosas masculinas y femeninas de inmigrantes europeos y de nacionales, las cuales sustituyeron al Estado, en el $65 \%$ del territorio nacional entre finales del siglo XIX y las primeras décadas del siglo XX. ${ }^{8}$

\section{Anotaciones sobre las relaciones Iglesia-Estado en América Latina en el siglo XIX}

En América Latina, las Iglesias nacionales atravesaron, durante el siglo XIX, por períodos diversos y con ciertos grados de variabilidad en las relaciones Iglesia-Estado, por lo que es casi imposible establecer una periodización precisa. Con todo, puede afirmarse que, en la casi totalidad de los paises, la lucha por establecer procesos de secularización en sus sociedades o por mantener las tradiciones católicas y un régimen de cristiandad, fue favorable a la primera opción. ${ }^{9}$ Sin embargo, en el caso colombiano, se produjo un proceso secularizador entre 1810 y 1885, que fue modificado radicalmente por un proyecto confesional a partir de 1886. Siguiendo las tendencias propuestas y las agrupaciones temáticas ofrecidas por John Lynch en sus 
10

LYNCH, John. La formación de los Estados nuevos... Op. Cit., p.167.

11

GONZÁLEZ, Fernán. Poderes enfrentados... Op. Cit., p.130.

12

SAFFORD, Frank. Política, ideologia y sociedad. En: BETHELL, Leslie (ed.). Historia de América Latina. Tomo VI: América Latina Independiente, 1820-1870. Barcelona: Editorial Crítica, 1991. p.42-103; DEAS, Malcolm. Venezuela, Colombia y Ecuador. En: BETHELL, Leslie (ed.). Historia de América Latina. Tomo VI... Op. Cit., p.175-201.

13

SAFFORD, Frank. Política, ideología y sociedad... Op. Cit.

14

ANDERSON, Margaret Lavinia. Rivals and Revivals: Religion and Politics in NineteenthCentury Spanish America and Europe. En: IVEREIGH, Austen (ed.). The politics of religion in an age of revival. London: Institute of Latin American Studies, 2000.

15

RUDÉ, George. Europa desde las guerras napoleónicas a la revolución de 1848. Madrid: Cátedra, 1982. p.136-147.

16

HOBSBAWM, Eric. La era del capitalismo (1848-1875). Barcelona: Labor Universitaria, 1989. p.270. ya citados ensayos sobre la Iglesia católica, este autor afirma al respecto, "En casi todos los países de Iberoamérica, con la sola excepción de Colombia a partir de 1880, los gobiernos siguieron una política de secularización encaminada a limitar la influencia de la Iglesia en todos los aspectos de la vida aunque ningún régimen atacaba al catolicismo o al cristianismo como tal"10. Por su parte, el historiador Fernán González, afirma que "la periodización de los conflictos entre Iglesia y Estado en Colombia es muy distinta de la adoptada para el resto de América Latina, porque la dinámica de los conflictos es muy diferente: a partir de 1886, la Iglesia regresa a ocupar un papel dominante dentro de la estructura política de la nación, después de las situaciones conflictivas en torno al Patronato (1824-1853) y a las reformas liberales (1848-1886)"11. También, el historiador norteamericano Frank Safford y el británico Malcolm Deas, consideraron que en Venezuela, Nueva Granada (Colombia) y Ecuador, la Iglesia se debilitó con las reformas liberales, pero en el Ecuador y la Nueva Granada ella se resistió; la de este último país fue la más combatiente y difícil de someter, especialmente en las tierras altas de Cundinamarca, Boyacá y Pasto y en la católica Antioquia. ${ }^{12}$ Para Safford, el problema religioso fue muy agudo en Colombia, México, Ecuador y Guatemala y, si en los demás paises se logró una secularización amplia y una expropiación de los bienes de la Iglesia Católica, en Colombia ésta luchó palmo a palmo con el Estado liberal. ${ }^{13}$

Dado el carácter universal de la Iglesia, para el siglo XIX europeo, Margaret Lavinia Anderson señala que éste fue un siglo de resurgimiento católico y crecimiento del nacionalismo. ${ }^{14}$ George Rudé considera que, aunque las gentes del siglo XIX vivieron la decadencia de la venerable alianza entre la Iglesia y el Estado -excepto en España e Italia- y se produjo una crisis de fe, ésta no fue una época irreligiosa o escéptica, sino más bien una edad de tremenda vitalidad religiosa. ${ }^{15}$ El historiador Eric Hobsbawm, establece diferencias entre la tendencia general del periodo 1789-1848, durante el cual fue muy acentuada la secularización, y la segunda mitad del siglo XIX, cuando el laicismo se trenzó en ardua lucha contra las religiones establecidas: el catolicismo intransigente y ultramontano rechazó todo acuerdo intelectual con las fuerzas del progreso, de la industrialización y del liberalismo, y "se convirtió en una fuerza aún más formidable, tras el Concilio Vaticano de 1870, pero a costa de ceder mucho terreno a sus adversarios"16.

Mientras en Europa, los avances secularizadores fueron más drásticos en la primera mitad del siglo XIX, en Hispanoamérica fueron más decisivos en su segunda mitad, cuando aquellos se afirmaron en la mayoría de los países, lo que también ocurrió con los Estados liberales frente a la Iglesia, con sus correspondientes asaltos sobre las tierras eclesiásticas, indígenas y municipales. Sin embargo, en las nuevas repúblicas, esta confrontación no fue uniforme. Un factor importante para comprender la diversidad de relaciones entre las dos potestades, fue el desigual poder, riqueza e influencia cultural de la Iglesia en los diferentes países de Hispanoamérica. Donde la Iglesia tuvo numerosos miembros, significativos recursos y un alto peso en las mentalidades - casos de México y Colombia - fue más acusada la reacción liberal, pero poseyó mejores condiciones para defenderse, lo que incidió en una mayor violencia en sus conflictos, en especial, en sus guerras civiles. En los casos de Argentina, Uruguay, Venezuela y Paraguay, la Iglesia fue más débil, no provocó hostilidades fuertes al Estado y debió aceptar que sus privilegios disminuyeran paulatinamente. En Perú, Bolivia y 
LYNCH, John. La Iglesia Católica en América Latina, 1830-1930. En: BETHELL, Leslie (ed.). Historia de América Latina. Tomo VIII: América Latina, cultura y sociedad, 1830-1930. Op. Cit. p.65-122.

18

DEMÉLAS, Marie-Danielle; SAINT GEOURS, Ives. Jerusalén y Babilonia. Religión y política en el Ecuador, 1780-1880. Quito: Corporación Editora Nacional, 1988. Véase también LYNCH, John. La formación de los Estados nuevos... Op. Cit., p.131247. En especial hacemos referencia al apartado: 'La religión y la Iglesia'.

19

MARTINS, William de Souza. Igreja e Estado no Brasil oitocentista: um diálogo com "La Iglesia católica y la formación del Estadonación en América Latina en el siglo XIX. El caso colombiano", de Luis Javier Ortiz Mesa. Almanack, Guarulhos, n.06, $2^{\circ}$ semestre de 2013.
Chile, se produjo un equilibrio de poderes y una relativa estabilidad en las relaciones entre ambos. ${ }^{17}$ Ecuador vivió de manera sui generis una compenetración entre la Iglesia y el Estado, a tal punto que ambos poderes casi se confundían ${ }^{18}$, Jerusalén (la Iglesia) sometió a Babilonia (el Estado) hasta 1895, año de irrupción del movimiento de la costa contra la sierra quiteña, liderado por el liberal radical Eloy Alfaro. Centroamérica vivió un período de conservatismo y clericalismo hasta abrir sus compuertas en la década de 1870 a un proceso de liberalización y secularización, efecto, en buena medida, de su fragmentación y de las pugnas por la hegemonía regional entre la conservadora y católica Guatemala y el Salvador, liberal.

Por fuera del área hispanoamericana, la Iglesia católica en el Brasil monárquico, siguiendo los comentarios de William de Souza Martins, tuvo una tenue organización institucional y una carencia de articulación social y política de las propuestas ultramontanas; además, las ideas científicas y liberales no cedieron tanto espacio a la penetración del ideario ultramontano y corporativo eclesiástico, y el régimen republicano no hizo concesiones tan significativas a la Iglesia, como ocurrió en Colombia. El ejemplo más significativo del enfrentamiento entre las directrices seculares asumidas por los dirigentes republicanos y los practicantes de un catolicismo tradicionalista estuvo representado por los movimientos milenaristas de Canudos (Bahía, 1896-1897) y de Contestado (Paraná-Santa Catarina, 1912-1916), entre fines del siglo XIX y principios del siglo XX. Las indisociables relaciones entre la Monarquía y la Iglesia, se mantuvieron durante el período de Don Juan (1808-1821) y no fueron afectadas por las rebeliones de 1817 a 1824 en Pernambuco, cuando el clero participó en movimientos políticos de carácter liberal y radical en contra de la centralización política emprendida por Río de Janeiro. Más bien, durante el primer Reinado (1822-1831) y el período de las Regencias (1831-1840), segmentos del clero próximos a un liberalismo radical ampliaron las tentativas de control del Estado sobre la Iglesia. Así, en el Brasil monárquico, los dos mayores enfrentamientos políticos vividos por la Iglesia católica se sitúan en las décadas de 1820-1830, como se señaló, y a lo largo de la década de 1870, con ocasión de la "Cuestión religiosa", pero ésta última se debió más a cambios internos en el episcopado, influenciadas por alteraciones ocurridas en la Curia romana, por los efectos del Concilio Vaticano I y por el espíritu ultramontano que de alli se derivó para algunos prelados que se enfrentaron a la masonería y a sus impactos en el clero y los fieles. ${ }^{19}$

\section{La Iglesia católica en Colombia durante el siglo XIX: una periodización} Una periodización de las relaciones y los conflictos entre la Iglesia y el Estado en la Colombia del siglo XIX, podría sintetizarse de esta manera: un primer período, de 1810 a 1853, reveló las diversas actitudes y posiciones de los miembros de la Iglesia - jerarquías, clérigos, comunidades religiosas y feligreses - durante el periodo de independencia, entre 1810 y 1824 , y las luchas de poderes en torno al Patronato entre 1824 y 1853 . Un segundo período va desde la separación de la Iglesia y el Estado entre 1853-1855 y 1885, año final del federalismo y de los gobiernos liberales radicales. Después de un interregno conservador de 1855 a 1861, se produjeron medidas liberales contra la Iglesia, amparadas en la Constitución de 1863, una vez culminada la guerra civil federal (1859-1862), cuyo resultado fue la derrota del conservatismo y de la Iglesia. Tales medidas fueron la desamortización de bienes de manos muertas (1861), la inspección de los cultos (1863) 
20

LOAIZA CANO, Gilberto. Religión y nación. La Iglesia católica en el proceso de construcción de la nación (Colombia, siglo XIX). Texto inédito facilitado por el autor. p.6.

21

lbidem, p.5.

22

TORO JARAMILLO, Iván Darío. Clero insurgente y clero realista en la revolución colombiana de la independencia. En: Anuario de historia de la Iglesia, Pamplona, España, Universidad de Navarra, n.17, p.119-136, 2008.

23

LOAIZA CANO, Gilberto. Religión y nación... Op Cit., p.6.

24

TISNÉS, Roberto. El clero y la independencia en Santa Fé. En: Historia Extensa de Colombia. Tomo IV, Vol.12. Bogotá: Academia Colombiana de Historia, Lerner, 1971

\section{5}

LOAIZA CANO, Gilberto. Sociabilidad, religión y política en la definición de la nación. Colombia, 1820-1886. Bogotá: Universidad Externado de Colombia, 2011. p.34

26

GUTIÉRREZ, Jairo. Los indios de Pasto contra la República, (1809-1824). Bogotá: Instituto Colombiano de Antropología e Historia, 2007; SAETER, Steinar A. Identidades e independencia en Santa Marta y Riohacha, 1750-1850.

Bogotá: Instituto Colombiano de Antropología e Historia, 2005.

27

GÓMEZ HOYOS, Rafael. La revolución granadina de 1810. Ideario de una generación y una época. Bogotá: Temis, 1967.

Ibidem, p.305-307. y la educación laica (1870). Finalmente, un tercer período revela el papel dominante de la Iglesia católica en la sociedad colombiana bajo la Regeneración conservadora entre 1886 y 1902, año en que culminó la Guerra civil de los Mil Días (1899-1902).

\subsection{De la independencia a mediados del siglo XIX}

Desde 1810, para la sociedad neogranadina como para las demás de Hispanoamérica, estaba en juego la redefinición de la Iglesia católica y del catolicismo en el nuevo orden republicano, ya que desde su momento fundacional, la historia de la vida republicana fue una larga y compleja imbricación de los problemas de secularización con los de la construcción nacional. No se trataba sólo del lugar institucional de la Iglesia católica con respecto al nuevo Estado, también estaba en juego el lugar cultural del catolicismo en la nueva república; su relativización o no como factor de unidad nacional, como principio ideológico de organización de la sociedad. ${ }^{20}$

El proceso de independencia le permitió a la Iglesia católica desplegar su personal y, como institución del Antiguo Régimen, adaptarse a las exigencias y hostilidades de la vida pública, a las tareas básicas de organización de la nueva república y a los retos que implicaba la construcción de un nuevo orden político, hasta erigirse en "baluarte de un ideal de organización republicana"21 Ella disponía de una tradición de participación en la política colonial y sus miembros ya eran ideólogos y practicantes de las distintas formas de representación ${ }^{22}$; además, al llegar a 1810, era portadora de un acervo jurídico que le permitió ejercer un liderazgo en la construcción republicana. ${ }^{23}$ Jorge Tadeo Lozano, uno de los primeros gobernantes de la naciente república, calificó el proceso emancipador como "una revolución clerical", pues un tercio de los firmantes del acta del 20 de julio de 1810 en Bogotá fueron clérigos y, tres más, fueron líderes populares del motín, como ocurrió también en distintas regiones donde también tuvieron un peso significativo. Otros clérigos hicieron una contribución intelectual en la redacción y el diseño de cartas y proyectos constitucionales de repúblicas católicas, cuando el nuevo Estado se erigía en el protector de la única religión permitida, la católica. ${ }^{24}$ La figura del cura párroco estuvo presente en las reglamentaciones de las primeras prácticas electorales, las reuniones políticas y las lecturas de prensa en voz alta en ciudades, pueblos y sitios; sacerdotes católicos dieron muestras tempranas de sus dotes de escritores políticos ${ }^{25}$; otros fueron procesados y desterrados por el gobierno realista, mientras unos más tomaron las armas y desempeñaron papel importante en ejércitos y guerrillas o defendieron el Antiguo régimen, como en las dos ciudades fidelistas al rey, Pasto al sur y Santa Marta en la Costa Caribe. ${ }^{26}$

La Iglesia no tuvo que modificar sus sistemas de creencias sino perfeccionar su red de agentes y actividades, de alli que tomara rápidamente la iniciativa en el campo de las sociabilidades políticas y aportara en la legitimación religiosa de la independencia, desde los púlpitos, mediante catecismos populares, diálogos escritos, divulgación de periódicos republicanos, anónimos, sermones y novenas que se hicieron en favor o en contra de la independencia. ${ }^{27}$ Para el franciscano Diego Francisco Padilla en su periódico El Aviso al público, "la conservación de nuestra santa religión fue el principal objeto de la revolución de independencia", pues con ello se buscó evitar que fuera "presa de la rapacidad francesa" y que nuestros paises estuvieran expuestos "al libertinaje y la rapacidad religio$\mathrm{sa}^{\prime 28}$. Las intervenciones del clero en las pugnas entre realistas y patrio- 

independencia. En: Curso superior de Historia de Colombia, 1781-1950. Bogotá: Academia Colombiana de Historia, 1950.

Ibidem, p.134-135

31

BUSHNELL, David. El régimen de Santander en la Gran Colombia. Bogotá: El Áncora editores, 1984. p.242.

VILLEGAS, Jorge. Colombia: Enfrentamiento Iglesia-Estado, 1819-1887. Medellin: Centro de Investigaciones Económicas C.I.E., Universidad de Antioquia, 1977. p.1A

33

GÓMEZ HOYOS, Rafael. La Iglesia y el Estado en el Congreso de Cúcuta. En: Congreso Grancolombiano de Historia. Bogotá: Kelly, 1972. p.515-516. tas y en las contiendas civiles entre federalistas y centralistas durante la Patria Boba (1811 a 1815) son una muestra de la profunda encarnación del clero en la vida social y política de la época. ${ }^{29}$ No ocurrió igual cosa con la mayoría de los obispos, casi todos nacidos en España, nombrados por el rey, quienes se sabían funcionarios del Estado español. De alli que buena parte de ellos se alineó inicialmente en el bando realista. Ante estas situaciones, estuvieron dispuestas las vacancias que quedaron en manos, generalmente, de criollos patriotas, lo que en casos, favoreció cierto apoyo oficial de la Iglesia a la independencia. ${ }^{30}$

Para 1810, la Iglesia católica neogranadina contaba con una Arquidiócesis en Bogotá, y cinco diócesis, las de Antioquia y Popayán en el occidente, y las de Cartagena, Santa Marta y Panamá en el Caribe. Para ese mismo año, había 1.117 sacerdotes, entre clero secular y regular, para una población total estimada de 1.400 .000 habitantes; habia un sacerdote por cada 1.189 habitantes. Luego, en 1825, pasada la independencia, hubo un sacerdote por 1.287 habitantes, lo que revela la salida del país de sacerdotes realistas y la ampliación de las posibilidades de ascenso social en la nueva vida republicana por fuera de la estructura eclesiástica. ${ }^{31}$

Culminada la independencia, la Iglesia católica y el Estado colombiano tuvieron conflictos en una lucha por preeminencias, como lo anota el historiador Jorge Villegas:

\begin{abstract}
Al término de la independencia (1819) se disputan la hegemonía tres poderes: 1. La Iglesia Católica, poderosa, rica, organizada y con fuerte prestigio popular; 2 . El ejército, triunfador de la contienda contra España, que posee fuerza desmesurada en relación con la población (30.000 soldados en millón y cuarto de habitantes) [...]; 3. El Estado naciente, heredero del aparato colonial español, mas no de su experiencia, quien nace deficitario y abrumado por el gigantesco peso de las deudas de guerra. ${ }^{32}$
\end{abstract}

Las élites independentistas percibieron que era necesario entenderse con la Iglesia mediante acuerdos, pues su prestigio la llevó a considerarse un par del nuevo Estado. Simón Bolívar captaba muy bien el peso social y político de dicha institución, su decisivo aporte a la construcción estatal y nacional, y la importancia internacional del reconocimiento papal de la nueva república, a tal punto que, en el Congreso de Cúcuta (1821), no permitió que se discutiera sobre religión, porque sabía que no sería admitida la tolerancia de ninguna otra que la católica. Comprendía entonces las condiciones socio-religiosas del pais, con un realismo extraordinario, como lo señaló en estas palabras: "El pueblo de Colombia no se halla preparado para ningún cambio en materia de religión. Los sacerdotes tienen grande influencia en las gentes ignorantes. La libertad religiosa debe ser consecuencia de las instituciones liberales y de un sistema de educación gene-

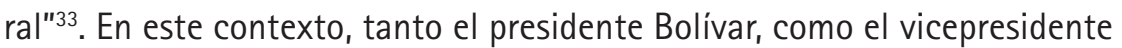
Santander, buscaron restablecer las relaciones con la Santa Sede y lograr el reconocimiento de la Nueva Granada como nación soberana, lo que se obtuvo en 1836. Desde unos años antes, los nuevos gobernantes eran partidarios de negociar un Concordato que ratificara el Patronato como privilegio del gobierno republicano, pero fue necesario que ascendiera al Papado Gregorio XVI, para que se produjera un entendimiento entre Roma y "los gobiernos de hecho", sobre los cuales Roma no se pronunciaba, pues el derecho a su soberanía tenía que ser de origen divino o no podía ser aceptado por el Papado. Entre tanto, el decreto orgánico de la dictadura de Bolívar del 27 de agosto de 1828 estableció la protección de la religión 
Cf. ELÍAS, Norbert. Los procesos de formación de Estado y de construcción de la nación. Historia y Sociedad, Medellín, n.5, p.101-117, diciembre 1998.

35

BIDEGAIN, Ana Maria (dir.). Historia del cristianismo en Colombia. Corrientes y diversidad. Bogotá: Taurus, 2004; PLATA William. Del catolicismo ilustrado al catolicismo tradicionalista. En: BIDEGAIN, Ana María (dir.). Op. Cit.

36

LOAIZA CANO, Gilberto. Sociabilidad, religión y política... Op. Cit., p.222. católica como la de los colombianos, misma afirmación que aparece en su mensaje al Congreso admirable de 1830.

Desde muy tempranamente, era obvio para el nuevo Estado republicano, que debía controlar el poder político que se derivaba del enorme peso social y moral de la Iglesia, pues aquel estaba escaso de legitimidad, sus rentas fiscales eran exiguas, su aparato administrativo precario y carecía de un sentimiento nacional que cohesionara suficientemente a la población. En estas condiciones, era difícil que el Estado se instaurara como aparato monopolizador de la fuerza, con plena autoridad en todas las regiones y localidades, y con amplio beneplácito por parte de sus habitantes. ${ }^{34} \mathrm{En}$ cambio, la Iglesia gozaba de una gran aceptación social, especialmente entre gran parte del pueblo, y de una distribución geográfica de su clero, que le permitía llegar a muchos de los rincones más apartados del territorio. Es por ello que, para los nuevos regímenes republicanos, el control patronal de la Iglesia católica se presentaba como una necesidad apremiante. Por su parte, los gobernantes liberales buscaban una mayor apertura a las ideas de la llustración y al mundo moderno - la libertad de conciencia y la tolerancia religiosa eran una clave para fomentar la migración europea de paises laicos y protestantes, aunque resultó muy débil - , por lo que no estaban dispuestos a una protección de la Iglesia que implicara perpetuar su monopolio ideológico, conscientes del poder y autoridad que ella poseía. Esta situación se había originado en la estrecha relación entre la Iglesia y el Estado español bajo la forma del Patronato Real, el cual convirtió a los reyes españoles en una especie de vicarios papales y generó un aislamiento casi total de las Iglesias hispanoamericanas de la Santa Sede y del resto del mundo católico. En esta condición, la Nueva Granada no abolió el Patronato regio, sino que le confirió una nueva forma jurídica, la figura del Patronato Republicano (1824), que asignaba al gobierno civil las funciones que antes tenian las autoridades españolas. De esta manera, la Iglesia y el Estado en la Nueva Granada estuvieron asociados, mediante formas conflictivas y conciliadoras, hasta la ruptura del Patronato Republicano en 1853.

El Patronato dio lugar a conflictos en los primeros años de la república. Entre 1821 y 1835, la Iglesia debió someterse a legislaciones que se constituyeron en un ultraje a su condición..$^{35}$ Desde la Constitución de 1821 se impuso la potestad del Estado, a través del Congreso, en la erección de obispados, en los límites de las diócesis y en la designación de obispos y arzobispos. Los intendentes provinciales intervenían en el nombramiento de curas y en la erección de parroquias; fueron suprimidos conventos y destinados a casas de educación, lo que se constituyó en uno de los detonantes de la guerra civil de los Supremos (1839-1842); hubo, asi mismo, conflictos en torno a la responsabilidad estatal sobre los diezmos y al exceso de días festivos, los cuales no fueron bien vistos por los reformadores ilustrados. Antes de aquella contienda bélica, miembros de la jerarquía y feligreses recurrieron a la difusión, desde el 10 de mayo de 1838, de las Sociedades Católicas que se expandirian por todo el país, interesadas en formar un partido católico para defender la tradición, participar en las elecciones republicanas para lograr el triunfo electoral de quienes pudieran legislar en favor de los intereses de la Iglesia católica, y para garantizar "la felicidad de la República cristiana"36. Las Sociedades enseñaban la doctrina cristiana, colaboraban con las fiestas del calendario religioso, competían por el control del mundo artesanal, difundían sus noticias en la prensa y luchaban contra la masonería y el "espiritismo", a 
38

GONZÁLEZ, Fernán. Poderes enfrentados... Op. Cit., p.146.

39

Para 1843, la Iglesia contaba con 1.268 clérigos y su relación con la población pasó a ser de uno por 1.523 habitantes; para 1851, la relación fue de uno por 1629 habitantes.

40

VILLEGAS, Jorge. Op. Cit., p.34.
JARAMILLO URIBE, Jaime. Esquema histórico de la Universidad Colombiana. En: Revista de la Cámara de Comercio, Bogotá, n.24, p.18-20, septiembre 1976. BOHOROUEZ CASALLAS, Luis A. La evolución educativa en Colombia. Bogotá: Editorial Cultural Colombiana, 1956. p.335-336.

42

SAMPER, José María [1881]. Historia de un alma Medellín: Editorial Bedout, s.f. p.181-182, p.189, p.233-234. Memorias escritas en 1881.

43

Ibídem, p.189. este último lo consideraban producto del protestantismo y fruto del libre albedrío y del individualismo. ${ }^{37}$

Las tensiones en las relaciones de la Iglesia y el Estado se agravaron, aún más, en 1836, cuando el Congreso dio jurisdicción a los tribunales civiles para juzgar a prelados y visitadores eclesiásticos y otorgó recurso de fuerza a los mismos tribunales en contra de las provisiones de jueces eclesiásticos. Con el Patronato Republicano, el Estado fue limitando algunos focos del poder eclesiástico, sin embargo, la resistencia de la Iglesia se produjo en el ámbito de la ley, la acción política, la guerra, las sociabilidades y sus prácticas, y mantuvo sus fortalezas en las mentalidades de sus feligreses.

Las cosas no iban bien para la Iglesia, pues aún en los gobiernos conservadores de José Ignacio de Márquez (1837-1841), Pedro Alcántara Herrán (1841-1845) y Tomás Cipriano de Mosquera (1845-1849), se presentaron intervenciones del poder civil en el poder eclesiástico. En 1840, se aprobó la ley que exigía el permiso del gobierno para divulgar las bulas papales; en 1841, se encargó por ley a los jefes de policía para que vigilaran a prelados y curas, para que no introdujeran novedades en la disciplina exterior de la Iglesia ni usurparan el Patronato, la soberanía, las prerrogativas de la república y la autoridad del poder civil. ${ }^{38}$ El gobierno de Mosquera trató, sin lograrlo, de legislar en contra de la inmovilidad de los censos eclesiásticos en 1847 y en contra de la acumulación de bienes en manos de la Iglesia en 1849 - los consideraba una "rémora para el progreso económico" y una "reliquia del hominoso feudalismo"; también propuso un impuesto general para el sostenimiento del culto, en vez del diezmo que afectaba la agricultura, a lo que se opuso el Encargado de Negocios de la Santa Sede y se presentaron reacciones clericales. Ese mismo gobierno, en 1849, propuso derogar el Patronato para evitar más conflictos, dotar al clero $^{39}$ y reconocer las instituciones monásticas y religiosas como "meras asociaciones morales [...] derogando todo fuero y dejando a los ministros religiosos sin ningún carácter de autoridades civiles o de funcionarios del régimen político"40. A lo anterior, estuvo asociada la discusión sobre el deslinde entre los partidos nacientes con respecto a la religión católica, en el cual fue decisiva la orientación de la educación y el papel de los jesuitas en la Nueva Granada. Éstos últimos habían sido traídos de nuevo por el gobierno conservador de Herrán después de su expulsión por el rey Carlos III en 1767. Así las cosas, Mariano Ospina Rodríguez, Secretario de lo Interior del gobierno de Herrán, reaccionó contra el Benthamismo, para imponer el catolicismo y el derecho romano como directrices de la política educativa, pues al culminar la Guerra de los Supremos (1839-1842), ya había clericalizado la educación superior y reemplazado el estudio de Bentham y de De Tracy por el de Heinecio y Balmes. ${ }^{41}$

La llegada de los jesuitas en 1844 introducía un nuevo elemento de polémica entre los partidos. Traídos inicialmente para los colegios de misiones, los jesuitas fueron pronto encargados de la educación de los jóvenes de clases altas de las principales ciudades. Esto los convirtió en bandera política y centro de controversia. José María Samper, ferviente masón, contaba que la Logia de Bogotá añadió el juramento de "guerra contra los jesuitas" a su programa político ${ }^{42}$; además, los jesuitas eran considerados por los liberales como auxiliadores políticos del partido conservador. ${ }^{43}$ En este ambiente, la nueva generación de jóvenes liberales, formados en el utilitarismo de Bentham difundido por Ezequiel Rojas, quien elaboró el primer programa del partido liberal en 1848 , y liderados por el liberal 
MOLINA, Gerardo. Las ideas liberales en Colombia. Bogotá: Universidad Nacional de Colombia, 1970. p.17-18.

45

ROJAS, Ezequiel. La razón de mi voto. El Aviso Bogotá, n.26, 16 de julio de 1848 .

46

DIRECTORIO NACIONAL CONSERVADOR. LOS programas conservadores de 1849 a 1949. Bogotá: Editorial Tipográfica Voto nacional, 1952. p.120-121.

47

RESTREPO, Juan Pablo. La Iglesia y el Estado en Colombia. Londres: Emiliano Isaza, 1885.

48

HORGAN, Terrance. El Arzobispo Manuel José Mosquera. Reformista y pragmático. Bogotá: Kelly, 1977. p.81-92.

GONZÁLEZ, Fernán. Poderes enfrentados... Op. Cit., p.153.

50

COLMENARES, Germán. Partidos políticos $y$ clases sociales. Bogotá: Universidad de los Andes, 1968. p.33, p.85-86.

51

BENZO, Camilo, Conde de Cavour. Libera Chiesa in libero Stato. Genova: II Melangolo, 2001. radical, Manuel Murillo Toro, se opusieron al Patronato, el centralismo, el autoritarismo y el ejército permanente. ${ }^{44}$ En aquel programa, afirmaba Rojas, "quiere el partido liberal que no se adopte la religión como medio de gobernar", sino que el Estado y la Iglesia giren cada uno en su propia órbita, pues el uso político del clero y la religión los envilece a ambos y los separa de sus fines. ${ }^{45}$ Por su parte, Mariano Ospina Rodríguez, en el primer programa del partido conservador en 1849, tomó la defensa del catolicismo como tema central y consideró que su partido "es el que reconoce y sostiene [...] la moral del cristianismo y sus doctrinas civilizadoras contra la inmoralidad y las doctrinas corruptoras del materialismo y del ateísmo"46. Las tensiones políticas y religiosas debilitaron y desgastaron las alternativas conservadoras, que habian estado activas durante el régimen de los 12 años (1837-1849), lo que trajo como consecuencia el ascenso de los liberales al poder político en 1849 y la puesta en acción de sus reformas, asociadas a las libertades, la afirmación de los derechos individuales y la suspensión de las tutelas religiosa y militar sobre el Estado.

La jerarquía eclesiástica en cabeza de su arzobispo, Manuel José Mosquera, no aceptó someterse a las leyes gubernamentales de libertad de cultos y elección de párrocos por los cabildos municipales - porque esto significaba la quiebra del principio jerárquico de la Iglesia católica -, ni a la expulsión de los jesuitas, por lo que fue expulsado del territorio neogranadino. Por su parte, los liberales querían controlar desde el gobierno la formación religiosa, liquidar los diezmos para romper con las relaciones de dependencia que tenía la Iglesia del Estado y establecer alianzas entre los curas párrocos y los jefes liberales, para mejorar sus resultados electorales. ${ }^{47}$ Como reacción a las medidas liberales y reformistas de mediados del siglo XIX, se profundizó la alianza de la jerarquía católica con el partido conservador, el cual asumió la defensa de la Iglesia y de los jesuitas, y le dio un intenso contenido emocional a la lucha interpartidista. ${ }^{48}$ Para Fernán González, "EI malentendido fundamental entre la Iglesia católica y [el] partido liberal iba a marcar profundamente la posterior historia de Colombia como un reflejo de las contradicciones de la iglesia universal con la problemática del mundo moderno. El problema básico no era tanto la fe católica como el sitio de la Iglesia en la sociedad civil y en el mundo político [...]"49. Asi mismo, tal como lo afirmó el historiador Germán Colmenares, no era la conciencia religiosa lo que estaba en juego, sino la existencia de un orden tradicional, en el cual la Iglesia estaba presente como el órgano social más prestigioso. ${ }^{50}$

\subsection{La Iglesia católica y el Estado liberal: la secularización y sus críticos (1853-1885)}

Con los enfrentamientos y las tensiones existentes bajo el régimen del Patronato, se abrió el camino para la separación entre la Iglesia y el Estado liberal en junio de 1853, bajo la fórmula de uno de los artífices de la unidad italiana, el Conde de Cavour (1810-1861), "Iglesia libre en Estado libre" ${ }^{51}$. Ello ocurrió dos años después de la guerra civil de 1851, obra de las reacciones de los terratenientes esclavistas Caucanos ante la abolición de la esclavitud, y de la oposición conservadora y clerical de la región de Antioquia a las medidas liberales que afectaban la propiedad, la familia, la religión y la división de su territorio, con sus lemas "Dios y Federación". Los conservadores y la Iglesia fueron derrotados en la guerra y las reformas liberales se harian realidad en la Constitución del 21 de mayo de 1853, que además de lo ya señalado, aprobó el librecambio; el sufragio universal de 
TIRADO MEJÍA, Álvaro. El Estado y la politica en el siglo XX. En: Nueva Historia de Colombia. Tomo II. Bogotá: Editorial Planeta, 1989. p.338.

53

Cf. GONZÁLEZ BERNALDO, Pilar. Civilidady politica en los orígenes de la nación argentina. Las sociabilidades en Buenos Aires, 1829-1862. Buenos Aires: Fondo de Cultura Económica, 2000

54

VILLEGAS, Jorge. Op. Cit., p.40-44

55

MOLINA, Gerardo. Op. Cit., p.80.

56

LOAIZA CANO, Gilberto. Sociabilidad, religión y política... Op. Cit., p.41.

57

GONZÁLEZ, Fernán. Poderes enfrentados... 0p. Cit., p.159-160. varones; las libertades individuales y de cultos; la abolición del ejército, de la pena de muerte, los diezmos y los censos; la separación de la Iglesia y el Estado; la abolición del fuero eclesiástico, las libertades de enseñanza, imprenta y palabra, de compra y venta de armas; el fortalecimiento de las provincias y la disminución de las funciones del poder ejecutivo. ${ }^{52}$

Los conflictos vividos bajo el Patronato convencieron a los liberales de la necesidad de separar el Estado de la Iglesia, para lo que debían fracturar principalmente la cohesión nacional que producia la religión católica en sus creyentes e iniciar un proceso de modernización de la sociedad.

Dicho proceso le permitiría al Estado reformado poseer la suficiente autoridad, legitimidad y poder para ejercer el control necesario sobre la sociedad o, al menos, intentarlo. Era necesario entonces debilitar a la Iglesia en su poder económico e inducirla a sostenerse por su propia cuenta; competir con las convicciones y creencias que se trasmitían en el púlpito y el confesionario, mediante la prensa, la tribuna pública y la educación, y disputarle sus adeptos en el campo de las sociabilidades y las formas de representación política. ${ }^{53}$

Un grupo de letrados liberales, que escribían en el periódico El Neogranadino, examinaron entre 1852 y 1853 las diferentes alternativas de la relación Iglesia-Estado liberal, afirmando que con el Patronato y el Concordato subsistirian las dificultades que habian dado origen a los conflictos, pues cuando el gobierno estaba en manos de ciudadanos liberales, ellos mantendrían la supremacía del poder civil sobre el eclesiástico y, cuando el gobierno fuera conservador se produciria una alianza entre gobernantes y sacerdotes. Aquellos letrados veían con temor la progresiva cercanía de la Iglesia al partido conservador y sostenían que en la Nueva Granada, "existe un partido cuya bandera, es por desgracia, la religión" ${ }^{\text {"5 }}$. En consecuencia, era necesario arrancarle de sus manos esa bandera, separando el poder espiritual del poder temporal y, así, garantizar la libertad de cultos. Además, en la misma dirección, argumentaban que el gobierno no tenía ni podía tener religión, cualquiera fuese la creencia del individuo que ejerciera el poder público. Dos de estos letrados, Florentino González y Manuel Murillo Toro, consideraban que el problema consistía en la excesiva intromisión del clero en política, por lo que eran partidarios de la separación de la Iglesia y el Estado. Para el liberal radical, Manuel Murillo Toro: "Mi teoría es ésta: el Estado libre, las creencias y el culto libres. La práctica de esta doctrina requiere la recíproca confianza y el hábito de la tolerancia, que son las consecuencias del reconocimiento mutuo de los derechos de la sociedad civil y los de las asociaciones religiosas" 55 .

Colombia se constituyó en el primer país de América Latina en formular, mediante una ofensiva reformista, la separación de la Iglesia católica y el Estado. ${ }^{56}$ Casi todos los liberales letrados sostenían que la unión entre la Iglesia y el Estado era fuente de tiranía, hipocresía y corrupción, y que la religión no podía desempeñar su misión, mientras no se le devolviese su independencia primitiva. En cambio, la mayoría del clero y la jerarquía se oponían a la separación, porque para ellos el estado normal de la relación de las dos potestades era el de la unión que, se suponía, debía permitir la colaboración mutua sin obstaculizar la recíproca libertad de cada una dentro de su esfera de acción. ${ }^{57}$ Se trataba de la instauración de un Estado para lo público y una religión para lo privado, sin que el Estado en su funcionamiento dependiese o se organizase en salvaguarda de la Iglesia. Ello significó también la prohibición de la contribución forzosa para el culto 
GONZÁLEZ, Fernán. Partidos políticos y poder eclesiástico. Reseña histórica 1810-1930. Bogotá: Cinep, 1977. p.115.

59

El Liberal. Bogotá, n.6, 25 de diciembre de 1853.

60

GONZÁLEZ, Fernán. Partidos, guerras e Iglesia en la construcción del Estado Nación en Colombia (1830-1900). Medellín: La Carreta Editores, 2006 p.62-63.

61

HOBSBAWM, Eric. Notas para la historia de las clases subalternas. En:_._. Marxismo e historia social. México: Universidad Autónoma de Puebla, 1983. p.45-59.

62

Cf. RUDÉ, George. La multitud en la historia. Estudio de los disturbios populares en Francia e Inglaterra, 1730-1848. Buenos Aires: Siglo XXI Editores, 1971.

63

"A partir de la segunda mitad del siglo XIX, los movimientos liberales impusieron por la fuerza un proceso de secularización. Uno de los casos más notorios es la Constitución Mexicana de 1857 y las Leyes de Reforma [...] Un caso similar fue el de la Constitución de 1863 en Colombia acompañada de la Inspección de los cultos desde 1861 hasta $1867 . .$. pero, en los demás paises de la región se promulgaron constituciones menos radicales que dejaron en una posición privilegiada a la Iglesia católica, aunque gradualmente fue reconocido el derecho a la libre práctica de otros cultos", BASTIAN, Jean-Pierre. La mutación religiosa de América Latina. Para una sociología del cambio social en la modernidad periférica. México: Fondo de Cultura Económica, 1997. p.35. religioso, la negación del carácter público de las corporaciones religiosas y la sanción posterior de la ley sobre libertad religiosa en 1855, en la que se declaró que "no hay religión del Estado", y se instituyó el matrimonio civil obligatorio y el divorcio vincular. ${ }^{58}$

Los nuevos cambios confirmarán a los liberales la idea de avanzar en la creación de un Estado moderno, en el cual, la Iglesia católica no se inmiscuya en los asuntos políticos. Sin embargo, rápidamente, la prensa liberal se quejaba de los abusos de prelados en la imposición de sus propias contribuciones y de los cobros de los sacerdotes para con sus feligreses, lo que hacía temer a muchos que la libertad absoluta en materia religiosa y de contribuciones, pudiera producir un mal que consistía en que "los pueblos ignorantes" fueran explotados por los párrocos. Además, armado el clero con el poder espiritual y el poder de la riqueza, podía convertirse en una potencia que moviera la república en el sentido que mejor le conviniera..$^{59}$ Esa separación entre la Iglesia y el Estado, tuvo muy corta vigencia, pues se suspendió en 1855, después de los temores que dejó en las élites neogranadinas la guerra civil de 1854, en razón del levantamiento plebeyoartesanal contra las políticas de librecambio, la liquidación del ejército y la libertad de cultos. Ante una Iglesia que usaba de su independencia para cuestionar el gobierno liberal y favorecer a los conservadores y, en medio de un período de auge de los sectores populares con sus protestas y resistencias al modelo del laissez-faire, los jefes liberales radicales y los conservadores se aliaron para derrotar al líder del golpe "artesano-militar", José María Melo, a través de un consenso sobre la necesidad de mantener la inclusión de las masas populares, pero subordinadas a las directivas y controles de los partidos, a través de mecanismos clientelistas. ${ }^{60}$ "El miedo al pueblo" era una constante del siglo, y ambos partidos eran temerosos del "vulgo" o "la canalla", tal como denominaban a los sectores populares ${ }^{61}$; los liberales consideraban que era posible aliviar la situación de aquella "plebe", condicionando la adquisición de la ciudadanía al alfabetismo, la propiedad y la educación laica; en cambio, para los conservadores y la Iglesia católica, la presencia de "la multitud" o "el populacho" en la vida pública ${ }^{62}$ era considerada peligrosa si previamente no pasaba por el tamiz de los valores del cristianismo trasmitidos por una educación católica dirigida por la Iglesia. En consecuencia, "el pueblo", según ambos partidos, aún no estaba preparado para la democracia.

Culminada la guerra de 1854 , se formaron dos gobiernos conservadores consecutivos entre 1855 y 1861, en los que la Iglesia, a pesar de las críticas liberales, se recompuso provisionalmente. En el gobierno dirigido por el conservador Mariano Ospina Rodríguez (1857-1861), defensor de la Iglesia y de los jesuitas, se inició la guerra civil federal que concluyó en 1863 con la derrota del conservatismo y la Iglesia católica, y se produjo el triunfo de los opositores liberales en la única guerra civil colombiana en la que vencieron los rebeldes. El partido vencedor le dio al país una nueva constitución hegemónicamente liberal en 1863 y sometió la Iglesia al control del Estado. ${ }^{63}$ Estos fenómenos se comprenden mejor en el contexto de la situación de la Santa Sede frente a la República Francesa, la Unidad Italiana y las luchas Carlistas en España, los cuales repercutirán en las relaciones con las repúblicas hispanoamericanas: la creciente pérdida del poder político del Papa en Italia se verá compensada con una tendencia a la centralización mayor de los asuntos eclesiásticos en Roma, es decir, a "la romanización de la Iglesia católica", cuyos principales instrumentos serán 
KREBS, Ricardo. La Iglesia de América Latina en el siglo XIX. Santiago de Chile: Ediciones Universidad Católica de Chile, 2002. Véase el capítulo 5.

65

ROJAS GARRIDO, José María. Discurso en la Convención de Ríonegro. En: Los radicales del siglo XIX. Escritos políticos. Bogotá: El Áncora, 1994. p.119.

66

PARRA, Aquileo. Memorias. Bogotá: Imprenta La Luz, 1912. p.356-357.

67

DÍAZ CASTRO, Eugenio. Manuela. Bogotá: Periódico El Mosaico, 1858-1859, por entregas. La librería Garnier de Paris publicó esta obra como libro en 1889.

68

ANCIZAR, Manuel. Peregrinación de Alpha. Por las Provincias del Norte de la Nueva Granada, 1850-1851. Bogotá: Echeverría, 1853. los nuncios pontificios y los jesuitas. Esta tendencia centralizadora chocará con las orientaciones de los nuevos Estados hispanoamericanos. De otra parte, las relaciones de la Iglesia con el mundo moderno de la llustración y de la Revolución Francesa, agudizarán aún más las tensiones con los Estados liberales hispanoamericanos. Por su parte, el Carlismo tendrá una presencia significativa en las ideas prohispánicas y ultramontanas del catolicismo y el conservatismo colombianos, e impregnará instituciones y guerrillas cuyas prácticas convergieron en el lema "Dios, patria y libertad"64.

Durante y después de la guerra federal (1859-1863), los gobiernos de Tomás Cipriano de Mosquera (1861-1863) y Manuel Murillo Toro (1864-1866) tomaron medidas contra la Iglesia: la expulsión del delegado apostólico, de algunos obispos y de los jesuitas, por su participación directa en la guerra a favor del partido conservador; fueron decretadas la desamortización de bienes de manos muertas (texto tomado, casi exactamente, del decreto de desamortización mexicana) y la inspección de los cultos por parte del Estado, que otorgaba al gobierno el control de las actividades del clero.

Las medidas contra la Iglesia fueron objeto de discusión en la Convención liberal de 1863. Allí, liberales autoritarios como Tomás Cipriano de Mosquera y José María Rojas Garrido, buscaron controlar las actividades de la Iglesia, argumentando que la mayoría de los obispos y clérigos se habian identificado con el partido conservador en la guerra, y debía negárseles la ciudadanía porque eran "soldados extranjeros de Roma". Ellos eran conscientes de que el partido liberal no tenía instrumentos para controlar a la Iglesia y que no podía "competir electoralmente con el poder del confesionario"65. Por su parte, los liberales radicales se oponían a que la jerarquía y el clero ocuparan un lugar privilegiado en la sociedad, pero eran partidarios de la libertad religiosa, de la cual no podian excluir a la Iglesia porque traicionarian sus principios. ${ }^{66}$ Finalmente, el acuerdo que se impuso en la Convención de Rionegro fue el del juramento de obediencia por parte de los ministros a la constitución, leyes y autoridades civiles, con pena de destierro para los que no se sometieran; la imposibilidad para los ministros de elegir y ser elegidos y de ocupar cargos, empleos y servicios públicos; la prohibición del establecimiento de comunidades religiosas regulares; el levantamiento de los destierros y confinamientos previa sumisión y fianza entre mil y diez mil pesos, y un permiso obligatorio de la autoridad civil para ejercer sus funciones.

A pesar de las medidas impuestas a la Iglesia, su peso social no podía contrarrestarse con la simple expedición de aquellas. Los jerarcas y numerosos sacerdotes se opusieron a ellas porque las consideraron usurpaciones de la autoridad temporal. En cualquier caso, la Iglesia controlaba "la cátedra de la verdad" por medio del púlpito, donde se enseñaba y no se discutía; además, el pueblo no leía, pero si oía sermones, aún más, se cohesionaba por medio de la religión, tal como señaló el sacerdote de la novela Manuela del literato Eugenio Díaz Castro, "a nosotros nos oyen cada ocho días y, se lo diré sin vanidad, nos creen"67.

Los informes de la Comisión Corográfica dirigida por Agustín Codazzi (1851-1859), entre ellos La Peregrinación de Alpha ${ }^{68}$, escrita por Manuel Ancizar Basterra - primer rector de la Universidad Nacional de Colombia en 1867 - , y memorias de Viajeros nacionales y extranjeros del siglo XIX, dejan ver una sociedad bastante tradicional, cuyas vidas se tejen en los distritos y parroquias rurales en una población de 2.900 .000 habitantes en 1870 o un poco más de 4 millones en 1900, gobernados por una tetrarquía 
69

ARANGO DE RESTREPO, Gloria Mercedes. $L a$ mentalidad religiosa en Antioquia. Prácticas y discursos, 1828-1885. Medellin: Universidad Nacional de Colombia, Sede Medellin, Facultad de Ciencias Humanas y Económicas, 1993. CORTÉS, José David. Curas y políticos. Mentalidad religiosa e intransigencia en la diócesis de Tunja. Bogotá: Ministerio de Cultura, 1998. LONDOÑO VEGA, Patricia. Religion, Culture and Society in Antioquia, Colombia, 1850-1930. Oxford: Oxford University Press, St. Antony's College, 2002. ARANGO DE RESTREPO, Gloria Mercedes. Sociabilidades católicas, entre la tradición y la modernidad. Antioquia, 1870-1930. Medellín: Universidad Nacional de Colombia-DIME, 2004; Idem. Estado Soberano del Cauca: asociaciones católicas, sociabilidades, conflictos y discursos político-religiosos, prolegómenos de la guerra civil de 1876. En: ORTIZ MESA, Luis Javier et al. Ganarse el cielo defendiendo la religión... Op. Cit.

70

LONDOÑO VEGA, Patricia. La política de la religión en una sociedad que se moderniza: Antioquia (Colombia), 1850-1910. En: Nineteenth-Century Workshop/Conference The politics of religión. London: Institute of Latin American Studies, 22 may, 1998.

71

Cf. BRAUDEL, Fernand. La larga duración. En: La Historia y las Ciencias Sociales. Madrid: Alianza Editorial, 1990. p.60-106.

72

LONDOÑO VEGA, Patricia. La política de la religión... Op. Cit., p.13-14.

73

Véase ARANGO DE RESTREPO, Gloria Mercedes y ARBOLEDA MORA, Carlos. La Constitución de Rionegro y el Syllabus como dos símbolos de nación y dos banderas de guerra. En: ORTIZ MESA, Luis Javier et al. Ganarse el cielo defendiendo la religión... Op. Cit.

74

GONZÁLEZ, Fernán. Poderes enfrentados... 0p. Cit., p.208-210.

75

JARAMILLO, Roberto Luis; MEISEL, Adolfo. Más allá de la retórica de la reacción, análisis económico de la desamortización en Colombia, 1861-1888. Cuadernos de historia económica y empresarial, Cartagena, n.22, p.1-62, diciembre 2008. parroquial compuesta por el cacique, el tinterillo, el cura y el alcalde. Si bien, los destellos de vida urbana avanzaban gradualmente desde los años 1850 y se produjo un nuevo paisaje cultural entre 1860 y 1880 bajo los gobiernos liberales, no obstante las mentalidades religiosas de las gentes, en gran medida, permanecen casi incólumes. Así lo han demostrado, los estudios de Gloria Mercedes Arango de Restrepo, Patricia Londoño Vega y José David Cortés Guerrero, sobre las mentalidades religiosas en Antioquia y Boyacá, y sobre las formas asociativas en las regiones antioqueña y caucana, respectivamente. ${ }^{69}$ Londoño muestra una Iglesia católica arraigada en Antioquia, inserta en la vida cotidiana de sus gentes, acicate para el progreso material, promotora de la educación e impulsora de asociaciones e instituciones, las cuales, entre 1850 y 1910, persiguieron objetivos culturales (282: bibliotecas públicas; agrupaciones literarias, artísticas y teatrales; sociedades científicas y pedagógicas; asociaciones para el fomento cívico o moral; bandas, conjuntos musicales, orquestas y academias de "música culta"; sociedades de temperancia y clubes sociales), devotos (251: cofradias, congregaciones, ligas, confraternidades y uniones) y de carácter filantrópico y de beneficencia (163: para proteger, educar, capacitar, curar y albergar a los enfermos y desvalidos y orientar a los trabajadores en una sociedad en iniciales procesos de urbanización a comienzos del siglo XX). ${ }^{70}$ Arango y Cortés presentan estudios de las mentalidades colectivas y de su permanencia en la larga duración ${ }^{71}$, a través de los discursos, prácticas e instituciones, tomando como base la alta participación de los feligreses en los sacramentos, la educación, la prensa y las funciones familiares. Para esos años, una comparación entre el total del clero parroquial y los católicos por párroco entre la católica Irlanda y Colombia, muestra que no obstante su importancia, ésta última estuvo menos presente que aquella en la vida de la población; para 1851, Irlanda, con 2.368 párrocos tuvo 2.214 católicos por párroco, mientras Colombia con un total de religiosos de 1.672, tuvo 1.100 habitantes por religioso; para 1871, la relación en Irlanda fue de 2.813 párrocos y 1476 católicos por párroco, mientras en Colombia había 1565 religiosos y 2.000 católicos por religioso. ${ }^{72}$

Empero, los problemas más álgidos que debió enfrentar la Iglesia fueron la desamortización de bienes de manos muertas, la inspección de cultos y la educación laica, a los que se asociaron otros de no menor importancia, como la actitud del clero en elecciones, la fundación de una universidad católica en oposición a la liberal, laica y "masónica" Universidad Nacional de Colombia fundada en 1867 por los radicales; y la relación de los escritores laicos con la jerarquía eclesiástica, quiénes más influenciados por el Syllabus errorum ${ }^{73}$ que por la Biblia, expresaban sus posiciones ultramontanas y propugnaban por la guerra contra el liberalismo. ${ }^{74}$

Con respecto a la desamortización, los bienes eclesiásticos fueron rematados entre 1861 y 1888, por un valor de 20 millones de pesos y comprados por comerciantes y hacendados, lo que le permitió a los gobiernos liberales, junto con los ingresos por aduanas de tabaco, quina, añil, oro y café, lograr una relativa estabilidad fiscal hasta 1876. Con ello, se debilitó el poder económico de la Iglesia secular y de las comunidades religiosas, al expropiarles bienes raíces, semovientes y censos para ser subastados entre el público. ${ }^{75}$ Por su parte, la inspección de cultos funcionó conflictivamente desde 1861 hasta el golpe de Estado que los liberales radicales propinaron al tercer gobierno de Mosquera en julio de 1867, lo que significó una transacción coyuntural de la política radical con respecto a la Iglesia. Los 
RESTREPO, Manuel Canuto. Pastoral que el llustrísimo Obispo de Pasto, Dr. Manuel Canuto Restrepo dirige a su clero y a sus diocesanos. En: Biblioteca Banco de la República de Pasto. Pasto: octubre 12 de 1872. p.3.

77

OSPINA RODRÍGUEZ, Mariano. La cuestión moral. La Civilización, n.2, p.9, 16 de agosto 1849. hechos punibles de los clérigos contra el orden público y contra la soberanía nacional fueron sometidos a la jurisdicción de sus tribunales ordinarios, lo que permitió el regreso del exilio del arzobispo de Bogotá, Monseñor Vicente Arbeláez, y de los demás obispos. Fue derogado el permiso gubernamental para los documentos papales y el juramento de obediencia a la Constitución por parte de los ministros de cualquier religión. A partir de este momento, el Arzobispo Arbeláez se acercó a los jefes más representativos del liberalismo radical y trató de mantener a los miembros de su grey por encima de los enfrentamientos partidistas, buscando evitar la instrumentalización del clero por parte del partido conservador, lo que profundizó en la Iglesia colombiana su división interna e hizo que el arzobispo se ganara la animadversión de los conservadores más interesados en ahondar los conflictos con el liberalismo, y de los obispos y el clero ultramontano. En sus pastorales, el arzobispo exhortó al clero para que no participara directamente en política ni apoyara candidaturas políticas, y para que los sacramentos fuesen administrados a todos aquellos que los solicitaran cualesquiera fuesen sus opiniones políticas, es decir, también a los liberales.

La política conciliadora del Arzobispo Arbeláez no fue bien vista por sus opositores. Pero, lo que polarizó las posiciones dentro de la Iglesia fue la aceptación o no de la reforma educativa laica de 1870 - basada en el modelo de enseñanza de Johann Heinrich Pestalozzi, Johann Friedrich Fröebel, Horace Mann y otros - que buscaba trasformar las mentalidades católicas en formas modernas de pensamiento y expandir esa nueva formación desde la educación primaria hasta la superior, bajo el liderazgo de la Universidad Nacional de Colombia. Los opositores a la reforma educativa consideraron que el sistema escolar liberal obedecía a un plan premeditado contra la Iglesia, que era parte del complot universal de todos los gobiernos liberales y masónicos del mundo que pretendian su total destrucción. ${ }^{76} \mathrm{Al}$ tiempo, el arzobispo buscaba transacciones con los radicales para mantener la enseñanza de la religión en las escuelas sin oponerse tozudamente a la reforma educativa. En ese ambiente, un importante grupo de obispos y clérigos incendiaron la guerra civil de 1876.

Es notorio entonces por qué la Iglesia católica, ante el avance político e ideológico de los liberales, debió competir con ellos en los campos de la prensa, la creación de opinión pública, las prácticas asociativas y la educación. Al tiempo que los liberales incrementaron la educación, construyeron caminos, le dieron fuerza a la navegación a vapor e iniciaron los ferrocarriles, sus periódicos y sociedades tuvieron años de esplendor entre 1860 y 1880 , y las sociedades y asociaciones - entre ellas, 36 logias masónicas existentes en el país - también tuvieron importancia en la creación de un nuevo paisaje cultural, pero debieron combatir, principalmente con las tradiciones eclesiásticas heredadas.

Mariano Ospina Rodríguez, había señalado lúcidamente a mediados del siglo, que la Iglesia debía responder al liberalismo con instrumentos contundentes, tales como la predicación, la asociación y la enseñanza. ${ }^{77} \mathrm{El}$ paso del tiempo y sus estrategias le darian la razón, ella logró imponerse en esa lucha por la hegemonía al constituirse en un eficaz agente político que adaptó su estructura y su funcionamiento a las nuevas condiciones para competir por el predominio en la vida pública y derrotar las tentativas secularizadoras de la dirigencia liberal. Su decisivo ascendiente en la vida pública colombiana del siglo XIX y, sobre todo, su influjo en el tipo de nación que debía construirse fue el resultado de la formación y consolida- 
Las mujeres en el frente de la caridad cristiana contribuyeron a consolidar la matriz cultural del conservatismo, a través de numerosas prácticas: visitas directas a los pobres y a las prisiones, dirección de hospitales, fundación de escuelas y talleres para niños huérfanos; también tuvieron papel protagónico en los bautismos, las primeras comuniones y los matrimonios masivos; estos fueron algunos de los más inmediatos logros del despliegue femenino en el campo de la caridad. LOAIZA CANO, Gilberto. Religión y nación... Op. Cit., p.4, 21.Véase también: CASTRO CARVAJAL, Beatriz. Caridad y beneficencia. El tratamiento de la pobreza en Colombia 1870-1910. Bogotá: Universidad Externado de Colombia, 2007.

79

ARANGO DE RESTREPO, Gloria Mercedes. La mentalidad religiosa en Antioquia... Op. Cit. LONDOÑO VEGA, Patricia. Religion, Culture and Society in Antioquia... Op. Cit. LOAIZA CANO, Gilberto. Sociabilidad, religión y política... Op. Cit.

80

La devoción a la Virgen María y el papel decisivo de las mujeres católicas en la defensa de su Iglesia, se expresó en lo que algunos autores han calificado como "una verdadera sacralización de la mujer". CHOLVY, Gérard; HILLARIE, Yves-Marie. Histoire religieuse de la France contemporaine, 1800-1880. Toulouse: Editions Privat, 1985. p.171-176.

81

Entre los principales periódicos conservadores de orden nacional, se encontraban La Civilización. Bogotá, 1849-1851; El Tradicionista. Bogotá, 18711876; La Unión católica. Bogotá, 1871-1872; El Católico. Bogotá, 1863-1866; La Caridad, "Libro de la familia cristiana". Bogotá, 1864-1882; En la década de 1870 se destacaron en las regiones, La Sociedad. Medellín, 1872-1876; El Misionero. Barranquilla, 1870; La Semana religiosa. Popayán, 1875-1876; Los Principios de Cali. Cali, 1870-1871, 1875-1876. Los periódicos liberales más representativos fueron El Neogranadino. Bogotá, 1848-1851; El Diario de Cundinamarca Bogotá. 1870-1882, 1892-1893; El Relator. Bogotá, 1891-1904; El Espectador. Medellín, 1887. Un caso de uso eficiente de la Imprenta en una diócesis, se encuentra en SANTOS, Adriana. Conectarse con Dios en la frontera. Impresos católicos y sociedad: la experiencia del Magdalena durante los gobiernos radicales del siglo XIX. Historia y espacio, Cali, n.37, p.127-146, jul-dic/2011.

82

GUTIÉRREZ CELY, Eugenio. La política

instruccionista de los radicales: intento fallido de modernización de Colombia en el siglo XIX (18701878). Neiva: Foncultura, 2000. p.52.

83

Diario de Cundinamarca, Bogotá, n. 2350, 23 de agosto de 1877.

84

GONZÁLEZ, Fernán. Poderes enfrentados... Op. Cit., p.238-239. ORTIZ MESA, Luis Javier. Obispos, clérigos y fieles en pie de guerra. Antioquia, 18701880. Medellin: Facultad de Ciencias Humanas y Económicas de la Universidad Nacional de Colombia, Sede Medellín y Editorial de la Universidad de Antioquia, Colección Clío, 2010.

85

GONZÁLEZ, Fernán. Poderes enfrentados... 0p. Cit., p.239. ción de un personal político del catolicismo; de la expansión nacional de numerosas asociaciones, sobre todo en el frente de la caridad cristiana, y de su capacidad para extender una red de imprentas, librerías y bibliotecas que le dieron primacía a la producción y difusión de literatura católica. ${ }^{78}$ Así, la Iglesia, al ver amenazado su papel unificador y el control social que ejercía sobre la sociedad de la época, promovió modalidades que limitaran las aspiraciones liberales, mediante el incremento de sus formas asociativas, sociedades católicas, asociaciones femeninas, peregrinaciones, procesiones, cofradías, fiestas patronales e instituciones de beneficencia ${ }^{79}$; fortaleció su alianza con el conservatismo y aún con sectores independientes del liberalismo; participó activamente en las guerras civiles en defensa de sus fueros y los de sus fieles; fundó seminarios para mejorar la formación de sus sacerdotes con el objeto de defender la doctrina y debatir las tesis liberales; amplió el número de diócesis para estar más cerca de su grey; inauguró un siglo de catolicismo femenino ${ }^{80}$ que llevó aún más a las mujeres a la esfera pública; creó periódicos católicos y respaldó periódicos conservadores ${ }^{81}$; amplió su red de instituciones educativas católicas y tomó partido en los procesos electorales.

Por su parte, para los gobiernos radicales de los años 1870 a 1877, el obstáculo principal para el progreso no estaba en su geografía "sino en el alma y la mente de los colombianos, pues el analfabetismo, la ignorancia y el fanatismo religioso constituían la causa del atraso del pueblo y del dominio del clero sobre la conciencia popular"82. De alli que la educación fuera la base del desarrollo económico, por lo que la creación de la Universidad Nacional y la reforma educativa de 1870 se constituyeron en un objetivo político y cultural que permitiría "la propagación de una mentalidad racional y una moral secular, para barrer del suelo colombiano las telarañas y sabandijas de la colonia goda"83. Las tensiones de los conservadores y parte de los obispos y clérigos con el gobierno radical, detonaron la "guerra de las escuelas y de los curas" en 1876. Con ella se produjo un mayor endurecimiento de posiciones liberales que hasta entonces habian sido tolerantes como las de Manuel Murillo Toro y Aquileo Parra. Estos letrados vieron la necesidad de establecer un control estricto a la actividad del clero, por "su infernal influencia en las masas", al apoyarlas activamente desde los púlpitos, como informantes, reclutadores y capellanes de los batallones militares - con los nombres de "Pío IX", "Obispo de Popayán" y "Obispo de Pasto" -, los cuales llevaban banderas blancas y amarillas de los Estados Pontificios, y estandartes del Sagrado Corazón de Jesús. Al tiempo, la guerra afectó negativamente los graduales avances de la reforma educativa laica. ${ }^{84}$

Derrotados los conservadores y la Iglesia ultramontana, no se hicieron esperar las medidas de los liberales radicales. Los cinco obispos que "incendiaron la guerra" fueron desterrados por diez años y privados a perpetuidad de sus funciones episcopales; se suprimió el pago de la renta nominal eclesiástica o compensación por la desamortización y se restauró nuevamente la inspección de cultos que imponía restricciones a las funciones eclesiásticas y exigían el "pase" o permiso de los jefes políticos para llevarlas a cabo; pero ante todo imponian el sometimiento de clérigos y obispos a las leyes estatales. ${ }^{85}$

El liberalismo, unido coyunturalmente en la guerra y habiendo obtenido un triunfo pírrico, se dividió de nuevo al culminar la contienda bélica. Desde antes de la guerra, había surgido una facción disidente del liberalis- 
86

DELPAR, Helen. Rojos contra azules. El partido liberal en la política colombiana, 1863-1899. Bogotá: Procultura, 1994.

87

El profesor Guilherme Pereira das Neves, me interpeló con precisión en sus atinados comentarios, acerca de las razones por las cuales los liberales radicales no pudieron consolidar su proyecto estatal y nacional en la Colombia del siglo XIX. Por lo pronto, puedo ofrecerle esta interpretación al respecto. Acerca de otros aspectos, espero haber hecho puntualizaciones en este artículo, aunque sigo meditando sobre la parte tres de sus comentarios. Véase NEVES, Guilherme Pereira das. Comentários ao texto de Luis Javier Ortiz Mesa "La Iglesia católica y la formación del Estado-nación en América Latina en el siglo XIX. El caso colombiano". Almanack Guarulhos, n.06, 2semestre de 2013.

88

ALZATE GARCíA, Adrián. Asociaciones, prensa y elecciones. Sociabilidades modernas y participación política en el régimen radical colombiano, 18631876. 2010. Tesis (Maestría en Historia). Facultad de Ciencias Humanas y Económicas, Universidad Nacional de Colombia, Sede Medellín, Medellin, 2010. Véase la contraparte conservadora y católica en: LOAIZA CANO, Gilberto. Sociabilidad conservadora. En: Sociabilidad, religión y política... Op. Cit., p.213-316.

89

LANGLOIS, Claude. Le catholicisme au féminin revisité. En: CORBIN, Alain; LALOUETTE, Jacqueline (coord.). Femmes dans la cité, 1815-1871. Paris: Creaphis, 1996. mo radical, el liberalismo independiente, liderada por el abogado y político cartagenero, Rafael Núñez, quien buscó alianzas con el conservatismo y la Iglesia para llevar a cabo su proyecto "Regenerador". Dicha alianza tuvo sus inicios en el gobierno de Julián Trujillo (1878-1880), cuando, como efecto de la guerra, de los nueve Estados federales, seis quedaron bajo el dominio de los liberales independientes y tres bajo el dominio radical.

Desde 1880, las relaciones de la Iglesia y el Estado tomaron un nuevo rumbo porque los debilitados liberales radicales, decidieron buscar un modus vivendi acordado con la Santa Sede y la jerarquía eclesiástica. Los obispos desterrados fueron indultados y regresaron al país, y las leyes de inspección de los cultos fueron modificadas y atenuadas. Las tensiones no cesaron, pues los liberales radicales perdían fuerza en los Estados federales y en el Gobierno de la Unión, lo que los llevó a una guerra decisiva en 1885 que los colocó por fuera del espectro político. ${ }^{86}$

Derrotados los radicales, el presidente Rafael Núñez (1884-1886) declaró que la Constitución liberal de 1863 había dejado de existir y que se iniciaba un nuevo periodo que caracterizó con una frase lapidaria: "Regeneración fundamental o catástrofe". Así, puso en acción sus conceptos de centralización política en sustitución de la federación del Estado; de un orden estatal con autoridad refiriéndose peyorativamente a "la inestabilidad y desorden" del régimen liberal radical; de protección a la Iglesia católica, a la que consideró "tan vituperada en el período 1863-1880", cuando debería considerarse elemento esencial del orden social, y de exclusión del liberalismo radical de todo órgano de representación política.

Son múltiples las razones para comprender por qué los liberales radicales no pudieron consolidar su proyecto estatal y nacional. ${ }^{87}$ La división interna del partido liberal y la fuerza política e ideológica de sus opositores, los conservadores y gran parte de la Iglesia, se constituyeron en un freno casi permanente a sus proyectos. Las fuerzas militares que los habian respaldado fueron más favorables a sus contrapartes después de 1877; los propicios resultados electorales, a veces manipulados, durante los años 1863-1876, no los acompañaron en los años sucesivos, con lo que los empleos locales y provinciales fueron cada vez menores para sus adherentes. El sistema escolar nacional que se constituyó en la tentativa más ambiciosa para expandir un ideal republicano y laico, basado en la popularización de la escuela, tuvo desarrollos desiguales en las regiones, una vida relativamente breve y resultados modestos; incluso, de los 82.000 estudiantes que tuvo el pais en escuela primaria en 1876, la conservadora Antioquia contaba con el 22\%. También, a pesar de encontrarse en condiciones desfavorables, la Iglesia actuó de manera permanente en sus campos de acción luchando palmo a palmo por la lealtad de sus feligreses. La multiplicación de asociaciones y periódicos liberales en la segunda mitad del siglo, obligó a que la Iglesia llevara a cabo una expansión asociativa que tuviera en cuenta el control social y el proselitismo político-religioso ${ }^{88}$. Debió, en consecuencia, ofrecer alternativas a los problemas sociales mediante la difusión de la sociabilidad caritativa y evitar la expansión asociativa liberal, masónica y protestante. Estas acciones las llevó a cabo a través de la sólida alianza con una dirigencia laica que incluyó el activismo de mujeres de la élite y de sectores medios y populares, de modo similar a como ocurrió en otras sociedades ${ }^{89}$. Dicha alianza le dio consistencia organizativa al partido conservador y sustentó el proyecto de instauración de una república católica que se concretaría en el proyecto Regenerador (1886-1902) y en 
90

LOAIZA CANO, Gilberto. Sociabilidad, religión y política... Op. Cit., p.34-36.

Idem. Religión y nación... 0p. Cit., p.11.

92

lbídem. p.12.

93

GONZÁLEZ, Fernán. Poderes enfrentados... 0p. Cit., p.252.

94

JARAMILLO URIBE, Jaime. El pensamiento colombiano en el siglo XIX. Bogotá: Temis, 1964. p.295.

95

Ibídem. p.296.

96

Ibidem, p.322-326 la Constitución de 1886. Así "La Iglesia católica colombiana supo adaptarse al espacio hostil preparado por el reformismo liberal y logró imponerse en el desafío hegemónico que se la había planteado. Sus innovaciones asociativas fueron mucho más eficaces que las del liberalismo y aseguraron la implantación de un orden nacional católico"90.

"El fracaso de las iniciativas educativas laicas del liberalismo implicó el arraigo de la autoridad del sacerdote católico"91. Por tanto, la reorganización del clero colombiano, como en el resto de América Latina, se basó en el modelo del Concilio Vaticano I ( 8 de diciembre de 1868 18 de julio de 1870) en el cual se trataron temas tan importantes como la proclamación de la infalibilidad del Papa y la aplicación del Syllabus errorum de 1864. De tal manera que la reforma de la Iglesia católica en Colombia participó del proceso de reivindicación del ultramontanismo y de rechazo del mundo moderno. ${ }^{92}$

\subsection{Un Estado-nación católico y confesional (1886-1902)}

El año de 1886, marca el inicio de una nueva fase en las relaciones de la Iglesia con la sociedad y con el Estado. La reforma constitucional de 1886 y el Concordato de 1887 firmado con la Santa Sede, frenaron los conflictos entre la Iglesia y el Estado liberal, que habian caracterizado la mayor parte del siglo XIX colombiano. El pensamiento político con respecto a la Iglesia, que inauguró Rafael Núñez, asociado al intelectual católico Miguel Antonio Caro y al nuevo arzobispo de Bogotá, el jesuita José Telésforo Paúl, fue de suma importancia para modificar la posición que el Estado Colombiano había tenido con respecto a aquella. Núñez se distanció "de los elementos utópicos de la tradición política del liberalismo [...] se acercaba entonces a una concepción corporativa u organicista de la sociedad que otorgaba personería a entidades como la familia y la Iglesia"93. Una de las ideas más arraigadas en su pensamiento político fue la importancia que daba a las creencias religiosas como elemento de cohesión en la vida de los pueblos, sobre todo, de raigambre hispánica ${ }^{94}$. Por ello, consideró "que era imposible realizar ninguna tarea social y política del Estado en contra de los sentimientos católicos de la mayoría de la población y sin la colaboración de la Iglesia"95.

Para Núñez, el federalismo intensificó la anarquía en los países hispanoamericanos que, en su opinión, poseían gérmenes de disgregación, como el caudillismo, el individualismo y el localismo y, a su vez, sostuvo que la libre concurrencia y la separación hostil entre la Iglesia y el Estado produjeron inestabilidad política, de ahí que sus reformas buscaban establecer la paz religiosa, el centralismo político y un proteccionismo económico coyuntural para atraer a los artesanos. Por su parte, Miguel Antonio Caro, estaba interesado en "un Estado basado en los cuerpos orgánicos de la sociedad", en lo que es notoria la influencia del tradicionalismo francés de José de Maistre y Luis de Bonald. ${ }^{96}$

Las ideas de Núñez y Caro se plasmaron en la Constitución de 1886. En ella, "la nación" reconoce que la religión católica es la de la casi totalidad de los colombianos, de lo que se siguen los efectos de la personería jurídica de la Iglesia y la consonancia de la educación pública con el sentimiento religioso, reforzado por la firma del Concordato con la Curia Romana en 1887. En el acto de aprobación de la Constitución, Núñez hizo énfasis en que debían llamarse los sentimientos religiosos en auxilio de la cultura social y en que el sistema educativo debía basarse en la civilización 

1886. Bogotá: Plaza y Janés, 1983. p.30.

98 Ibidem, p.3-18.

EREGUREN, Juan Antonio. Derecho consuetudinario colombiano. Bogotá: Universidad Javeriana, 1961.

100

GONZÁLEZ, Fernán. Poderes enfrentados... 0p. Cit., p.259. cristiana, ya que ella era el "alma mater de la civilización del mundo"97. La Constitución se expidió, a diferencia de la de 1863, que lo hizo en nombre del Pueblo, en nombre de Dios, "fuente suprema de toda autoridad" y se declaró que "La Religión católica, apostólica y romana es la de la nación, por lo cual los poderes públicos se obligan a protegerla y hacerla respetar como elemento esencial del orden social" (artículo 38), pero se aclara - aunque así no ocurrió en sus prácticas - que la Iglesia ni es ni será oficial y conservará su independencia, pero los demás cultos tendrán libertad de ejercicio, mientras no sean contrarios a la moral cristiana ni a las leyes (artículo 10).

Por su parte, la educación pública fue organizada y dirigida en concordancia con la religión católica, con lo cual se puso fin a los enfrentamientos entre la Iglesia y el Estado. También, la Constitución le reconoció a la Iglesia personería jurídica, libre administración de sus asuntos interiores, libertad para ejercer autoridad espiritual y jurisdicción eclesiástica sin necesidad de autorización del poder civil. Eximió de impuestos a los templos católicos, seminarios y casas episcopales y curales, y declaró la incompatibilidad del ministerio sacerdotal con el ejercicio de los cargos públicos, excepto en la educación y la beneficencia. ${ }^{98} \mathrm{El}$ Concordato reiteró los aspectos ya señalados de la Constitución. La educación y la instrucción pública en universidades, colegios, escuelas se organizaron y dirigieron de conformidad con los dogmas de la religión católica (artículo 12), se otorgó a los obispos el derecho de inspección de los textos de religión y moral, y el gobierno se comprometió a impedir que se propagaran ideas contrarias al dogma católico y al respeto y la veneración debidas a la Iglesia católica; los obispos tuvieron la potestad de retirar a los maestros y la facultad de enseñar tales materias, si no lo hacían conforme a la doctrina cristiana (artículo13). Si bien la Santa Sede tenía derecho a nombrar arzobispos u obispos, el Papa, por deferencia y por conservación de la armonía entre las dos potestades, convino en someter los nombres de los candidatos a la consideración del presidente, para saber si tenía motivos de carácter civil o político para considerarlos no gratos (artículo 15). En cuanto al matrimonio de quienes profesaban la fe católica, éste produciría efectos civiles cuando se celebrase de acuerdo con el Concilio de Trento (artículos 17, 18 y 19).

De otra parte, el gobierno le reconoció a la Iglesia, en compensación por el valor de los censos y bienes desamortizados, una renta perpetua de $\$ 100.000$ colombianos, que iría aumentando a medida que mejorara la situación fiscal del gobierno, la cual se destinaría al auxilio de diócesis, cabildos, seminarios, misiones y otras obras eclesiásticas (artículo 24)..$^{99}$ En síntesis, la Iglesia hizo concesiones sobre sus derechos económicos pero a cambio del monopolio que ejercería en el sistema educativo. En estas condiciones, la Iglesia no necesitó una defensa ni una reflexión sobre la fe, lo que la hizo poco preparada para confrontarse con la modernidad, pluralista y secular que la rodeaba y con las corrientes ideológicas y culturales que imperaron en el resto del mundo. ${ }^{100}$ Finalmente, el Concordato aseguró el fuero eclesiástico.

La Constitución de 1886 tuvo una orientación de franca ruptura con la tradición federalista, liberal, secular e individualista heredada de la constitución de 1863. Con ello, estableció un régimen centralista, autoritario, presidencialista, católico y prohispánico. Consagró el carácter unitario de la nación y fortaleció los poderes del ejecutivo, extendió el período presidencial de dos a seis años y otorgó facultades extraordinarias al presidente que le permitieran imponerse sobre los demás poderes públicos. 
101

FARREL, Robert Vincent. The catholic Church and Colombian education: 1886-1930. En: Search of a Tradition. New York: Columbia University, 1974.

102

SÁNCHEZ, Gonzalo; AGUILERA PEÑA, Mario (eds.). Memoria de un pais en guerra. La guerra de los Mil Días. Bogotá: Editorial Planeta, 2001.

103

FISHER, Thomas. De la guerra de los Mil Días a la pérdida de Panamá. En: SÁNCHEZ, Gonzalo; AGUILERA PEÑA, Mario. Op. Cit., p.82.

104

MARTíNEZ, Frédéric. El nacionalismo cosmopolita. La referencia europea en la construcción nacional en Colombia, 1845-1900. Bogotá: Banco de la República-Instituto Francés de Estudios Andinos, 2001.

105

ORTIZ MESA, Luis Javier. La Regeneración en Colombia, 1878-1902. En: Colombia. Preguntas y respuestas sobre su pasado y su presente. Bogotá: Universidad de los Andes, Facultad de Ciencias Sociales y el Centro de Estudios Socioculturales e Internacionales (CESO), 2010.
Limitó la libertad de prensa y la libre asociación, restringió el comercio de armas, reimplantó la pena de muerte y centralizó la legislación y la fuerza pública. Restableció a la Iglesia católica como actor social de primer orden y la constituyó en el fundamento de la educación y del control social. ${ }^{101}$

La Regeneración acentuó la tendencia de la Iglesia católica, a aliarse con el partido conservador y excluir al partido liberal. Ello polarizó aún más la frontera divisoria entre los dos partidos tradicionales, centrada en "la cuestión religiosa". Dicha división tuvo, entre sus expresiones, la guerra de los Mil Días (1899-1902), que dejó como resultado 100.000 muertos, la bendición del bando conservador por las mayorias de la jerarquía y el clero, y la constatación por el obispo, hoy santo, Ezequiel Moreno de Pasto, de que "el liberalismo es pecado". Este fue el conflicto más trágico de la historia de Colombia hasta entonces, que marcaria los esquemas mentales del pais del siglo XX hasta el presente, con sus versiones apocalipticas y victoriosas. ${ }^{102}$ Ella reveló que "el Estado colombiano todavía era muy débil y se basaba sólo en un frágil consenso entre las élites"103, al tiempo que "la nación católica", afectada en muchos de sus miembros, se afirmaba.

La Regeneración fue una excepción dentro del contexto latinoamericano liberal y representó uno de los proyectos más importantes de construcción estatal en la Colombia del siglo XIX. ${ }^{104}$ En el campo ideológico, produjo una transformación en el discurso de la civilización, pues los conceptos de orden y autoridad se impusieron sobre el principio de libertad, y fue modificada la función social de la Iglesia católica. El nuevo discurso político tomó como punto de referencia a Europa. La denuncia del modelo francés, en la política y en la vida intelectual, visto como subversivo y anárquico, fue paralela a la exaltación de los logros de la "Europa conservadora", encarnada en las experiencias inglesa y española. En Inglaterra, el espíritu de libertad fue balanceado con la necesidad del orden. La imitación del "liberalismo conservador" ibérico, representado por el período de la Restauración de Antonio Cánovas del Castillo (1875-1885), convirtió a España en el principal modelo institucional de la Regeneración, en cuya correspondencia se impusieron medidas en Colombia, como la restricción a la libertad de prensa, el fortalecimiento administrativo, la modernización del ejército y la limitación del sufragio; también España fue el más importante referente de su lenguaje político. Esto se debió en gran medida a su carácter endógeno, que permitió asimilar la hispanidad a un elemento constitutivo de la definición nacional. Apoyada en esta idea, la referencia hispánica se impuso discursivamente como un culto a los ancestros y a las tradiciones.

La concreción del ideal de fundar el orden sobre la base del sentimiento religioso de la nación recayó en la función educadora de la Iglesia católica. En virtud del Concordato y con el fin de contrarrestar los efectos de la educación "utilitaria, materialista e impia", impartida durante el régimen radical, los regeneradores abrieron las puertas del pais a numerosas comunidades religiosas europeas, masculinas y femeninas, especialmente francesas, italianas y españolas, que habrian de dedicarse a labores educativas, dando inicio a un movimiento de inmigración religiosa, que se prolongó hasta las primeras décadas del siglo XX. También se ocuparon de actividades de beneficencia, caridad y misiones "civilizadoras de salvajes", término usado para referirse a la población indígena no evangelizada en la fe católica. ${ }^{105}$ 
106

COLMENARES, Germán. La ley y el orden social: fundamento profano y fundamento divino. En: Boletín Cultural y Bibliográfico del Banco de la República, Bogotá, n.22, vol. XXVII, 1990.

\section{7}

CÓRDOBA R., Juan Felipe. Las comunidades religiosas masculinas en Antioquia, 1885-1950. 2001. Tesis (Maestria en Historia). Facultad de Ciencias Humanas y Económicas, Universidad Nacional de Colombia, Sede Medellin, Medellín 2001. CASTRO H., María Patricia. Comunidades religiosas femeninas en Antioquia, 1876-1940. 2001. Tesis (Maestría en Historia). Facultad de Ciencias Humanas y Económicas, Universidad Nacional de Colombia, Sede Medellín, Medellín, 2001.

108

SÁNCHEZ, Gonzalo y AGUILERA PEÑA, Mario (eds.). Op. Cit.

109

Cf. VOVELLE, Michel. Ideologías y mentalidades. Barcelona: Ariel, 1985.

110

ABEL, Christopher. Política, Iglesia y partidos en Colombia, 1886-1953. Medellin: FAESUniversidad Nacional de Colombia, 1987.

\section{Consideraciones finales}

La Iglesia católica fue factor de construcción de Estado, de nación y de civilización occidental, a la vez que factor de polarización y ruptura de lazos de solidaridad. Elaboró un doble juego, crear y civilizar, de una parte, y destruir y polarizar, de otra. La perspectiva global para mirar este asunto podría ser la sugerida por el historiador Germán Colmenares acerca de nuestras sociedades hispanoamericanas, en las cuales se impuso un monismo religioso y autoritario tal, que el sistema político estaba dotado de una integridad, que encadenaba las relaciones sociales y el orden político a una doctrina uniforme. ${ }^{106}$ En dicho sistema, era muy difícil establecer una sociedad pluralista, al menos en el caso colombiano. En este contexto, la recristianización de la república creó su propio orden cultural, con el cierre de periódicos, la persecución a sociedades científicas y de librepensamiento, el estrechamiento de horizontes del sistema educativo y el profuso ingreso de comunidades religiosas masculinas y femeninas. ${ }^{107}$ Continuó su marcha el orden cultural católico, se impuso el Syllabus errorum sobre los proyectos liberales, lo que se percibe en la más directa participación de la Iglesia en política, en su rol dominante en el sistema educativo, en la mayor proliferación de asociaciones católicas, en el contenido religioso que se le imprimió a las fiestas y conmemoraciones patrias; en las restricciones a la libertad sexual, la censura al cine, la literatura y la indumentaria, en el control de la opinión a través de la prensa eclesiástica, los sermones y los confesionarios ${ }^{108}$, en fin, la Iglesia católica siguió, hacia el siglo XX, bien fundada y respaldada en las mentalidades ${ }^{109}$ que había construido de tiempo atrás y que siguió recreando, según las circunstancias modernas, para mantener un puesto decisivo en la nueva sociedad, y para asegurarse también que el Estado y sus ciudadanos, la mayoría creyentes, no estuvieran por fuera de la órbita de su doctrina y de su acción. ${ }^{110}$ 